VII Congreso de la SEdeM (Sociedad Española de Musicología). SEdeM (Sociedad Española de Musicología)-Universidad de Cáceres, Cáceres, 2008.

\title{
"O que vos nunca cuidei a dizer: musicología y filología en la edición del Cancionero del rey Don Denis".
}

\section{María Gimena del Rio Riande, Germán Pablo Rossi.}

Cita:

María Gimena del Rio Riande, Germán Pablo Rossi (Noviembre, 2008). "O que vos nunca cuidei a dizer: musicología y filología en la edición del Cancionero del rey Don Denis". VII Congreso de la SEdeM (Sociedad Española de Musicología). SEdeM (Sociedad Española de Musicología)Universidad de Cáceres, Cáceres.

Dirección estable: https://www.aacademica.org/gimena.delrio.riande/131 ARK: https://n2t.net/ark:/13683/pdea/eha

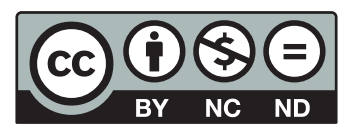




\title{
O que vos nunca cuidei a dizer: musicología y filología en la edición del Cancionero del rey Don Denis
}

\author{
Germán Pablo Rossi/ Ma. Gimena del Rio Riande \\ Universidad de Buenos Aires/ Universidad Complutense de Madrid
}

\section{Resumen}

El presente trabajo busca acercarse a las relaciones entre texto y música en la lírica profana gallegoportuguesa medieval, a través del análisis de tres cantigas con notación musical del rey Don Denis de Portugal que poseen problemas de tipo métrico que encuentran una posible solución en su performance. Se propone así un trabajo interdisciplinario donde la musicología resulta una rica aportación a los presupuestos de la crítica textual filológica de tipo neolachmanniana.

\section{Una aproximación interdisciplinaria al Cancionero del rey Don Denis}

Don Denis fue rey de Portugal desde 1279 a 1325 . Gobernante sagaz y culto, fundó la Universidad de Coimbra-Lisboa y allí la primera cátedra de Música, y fue también el más prolífico de los trovadores gallego-portugueses. De su extensa producción lírica se conservan 137 cantigas en dos apógrafos colectivos compuestos en Italia hacia 1525, el Cancionero de la Biblioteca Nacional de Lisboa (B), el Cancionero de la Biblioteca Vaticana (V), así como en el Cancionero de Berkeley o de la Biblioteca Bancroft (K), descriptor de este último. En el Fragmento de Torre do Tombo o Pergamino Sharrer $(\mathrm{T})^{1}$, folio suelto hallado en julio de 1990 por el Dr. Harvey L. Sharrer en el Archivo de Torre do Tombo en Lisboa, se encuentran los fragmentos de siete cantigas de amor del rey acompañadas de notación musical ${ }^{2}$. Este último posee un valor incalculable, ya que para el momento de su descubrimiento, la lírica gallego-portuguesa profana ${ }^{3}$ sólo se

\footnotetext{
${ }^{1}$ La referencia al Cancionero de Don Denis $(=C D D)$ parte del término liederbücher, acuñado por Gustav Gröber, (1877: 337-670), en sus estudios sobre lírica medieval occitana para señalar cancioneros individuales copiados en códices mayores. De la mano de la noción de liederbuch, el término cancionero se refiere a un libro que contiene piezas líricas -a veces acompañadas de melodía- compilado según un criterio unificador.

${ }^{2}$ Es de destacar el hecho de que en el momento de su descubrimiento el pergamino servía de contratapa para un registro de documentos notariales de Lisboa del año 1571. El pésimo proceso de restauración al que fue sometido lo ha dejado prácticamente ilegible. Consecuentemente, las autoridades del ANTT han prohibido su consulta.

${ }^{3}$ La tradición religiosa en gallego-portugués, testimoniada por las Cantigas de Santa María $(=C S M)$ de Alfonso X el Sabio, constituiría otra tradición aparte de ésta, musicalmente mucho más rica en cantidad. De todas formas, una y otra tradición estarían en contacto.
} 
encontraba musicalmente testimoniada por el Pergamino Vindel, una hoja volante con siete cantigas de amigo de Martin Codax.

En líneas generales, este mutiladísimo folio podría proceder de un cancionero individual, acaso del tan nombrado pero jamás hallado Livro de Trovas de D. Denis, o de un volumen colectivo (Sharrer 1992). Su estudio codicológico revela que habría sido producido tal vez en el scriptorium regio hacia fines del siglo XIII o principios del XIV, y a imitación de otros códices de gran tamaño como los de las $C S M^{4}$. Pueden detectarse dos estilos caligráficos en la escritura del material literario de parte del mismo copista; por el contrario, la música habría sido introducida por tres copistas diferentes (Ferreira 2005: 1 , nota 1$)$.

Teniendo en cuenta que en la Edad Media la lírica gallego-portuguesa constituía un repertorio lírico oral configurado dentro de la práctica musical, este trabajo propone acercarse al $C D D$ desde una perspectiva tanto musicológica como filológica, con el fin de arrojar luz sobre determinados problemas relacionados con la métrica y versificación de estos textos, y por ende, con la ecdótica y la historia de su edición crítica filológica.

\section{La importancia del aporte de la musicología en la edición crítica del $C D D$}

La sola noticia de que un texto lírico trae consigo su notación musical -como, gran parte del corpus de la lírica de oc y oil, las CSM, la producción de Martín Codax $^{5}$ o Don Denis-, trae implícito la revisión del trabajo filológico y la búsqueda de una complementariedad analítica entre la musicología y la filología. Es muy importante tomar conciencia de que la relación entre texto y música genera una interacción que completa el sentido de la composición, tanto en lo plasmado en los códices, como en el momento de la performance.

Para el caso de la lírica medieval en lengua romance, los elementos testimoniados a través de la notación musical apuntan a dar cuenta de las alturas relativas de los sonidos, de su disposición con respecto a las palabras (tanto en el nivel del verso como de estructuras más amplias), y en algunos casos, de la organización

\footnotetext{
${ }^{4}$ Curiosamente, dos de los testimonios conservados de las CSM, E y T, contienen algunos ejemplos de texto y pautado para la música a tres columnas. Fuera del ámbito peninsular, sólo un manuscrito francés de la primera mitad del siglo XIV, una versión del Roman de Fauvel, trabaja mayormente con folios a tres columnas (Sharrer 1993: 535).
} 
temporal y duración relativa de los sonidos ${ }^{6}$. Al proponer una articulación de sonidos predominantemente irregular para cada una de las sílabas de los versos, estos elementos ponen de relieve la importancia del fenómeno sonoro del texto en la performance trovadoresca. ${ }^{7}$

Mas cuando se vuelve sobre el texto de muchas ediciones de lírica profana gallego-portuguesa, puede a simple vista apreciarse el modo en que los editores olvidan esta dimensión, a través de enmiendas que se recortan sobre añadidos y supresiones, operando cambios sustanciales sobre los textos trovadorescos. Ya lo decía E. Asensio (1957: 432) acerca de J. J. Nunes, el primer gran editor de los corpora de amor y amigo, y su escuela: "corriendo tras una ilusoria regularidad, alteran, trasponen y corrigen textos legítimos". Años más tarde, y remitiéndose al $C D D$, volvería sobre el tema E. Gonçalves:

\begin{abstract}
Quem percorrer as edições da poesia de D. Denis (...) verificará que cerca de 70 versos foram considerados hipométricos e, por isso, emendados (...) Uma breve reflexão sobre estes dados sugeriu-me algumas dúvidas quanto à legitimidade da atitude crítica que consiste em resolver os problemas de edição de texto com a eliminação ou acrescento de palavras, a fim de obter, a todo custo, a isometría estrófica (...) limitar-nos-emos a observar o seguinte: a) uma aparente hipometría poderá significar que o poeta previu a existencia de uma pausa entre duas palavras cuja contiguidade produzia uma cacofonia (...) o estudo de M. P. Ferreira sobre a música do Pergaminho Vindel veio mostrar que determinadas intervenções tendentes a obter o issosilabsimo são perfeitamente desnecessárias (1991: 20).
\end{abstract}

Nuestra tarea será entonces intentar iluminar esta problemática a través de ejemplos donde la notación musical -con sus hipótesis interpretativas incluidascolabora al esclarecimiento de determinados problemas métrico-ecdóticos, con el fin de evitar la enmienda sistemática y promover la reflexión sobre estos loci critici.

\title{
3. El $C D D$ en su dimensión poética y musical
}

Cinco de las cantigas de $\mathrm{T}$ son de refrán o estribillo-tres de éstas tienen fiinda ${ }^{8}$-; y dos son de meestria. Una de éstas es la composición sobre la cual recortaremos nuestro análisis, O que vos nunca cuidei a dizer (T 3; B 526; VK 109), cantiga de coblas

\footnotetext{
${ }^{6}$ Esto último ha generado en muchos casos diferentes e interesantes teorías interpretativas que, por cuestión de espacio, no podemos analizar aquí.

${ }^{7}$ Para una aproximación a la notación musical en el $C D D$, ver Ferreira (2005: 49-58). Su Cantus coronatus constituye hasta el momento la única aproximación a las siete cantigas de Don Denis. Nos basamos en varias de sus hipótesis de trabajo para el análisis de nuestros ejemplos.

${ }^{8}$ En la tradición lírica profana gallego-portuguesa, cierre de la cantiga que puede tener entre dos o cuatro versos.
} 
unissonans (todas las estrofas poseen la misma rima), compuesta en metro decasílabo. Estas tres características formales, meestria, coblas unissonans y metro decasílabo, hacen de esta cantiga una composición muy cercana a las cansós occitanas. Desde su temática, la cantiga se recorta sobre la coita y el miedo (medo) que produce la senhor sobre el trovador, $\operatorname{topos}^{9}$ de larga data en la tradición amorosa cortés, ya tratado por Andreas Capellanus en el Segundo Libro de su De Amore, cuya regla XX dice: "Amorosus semper est timorosus":

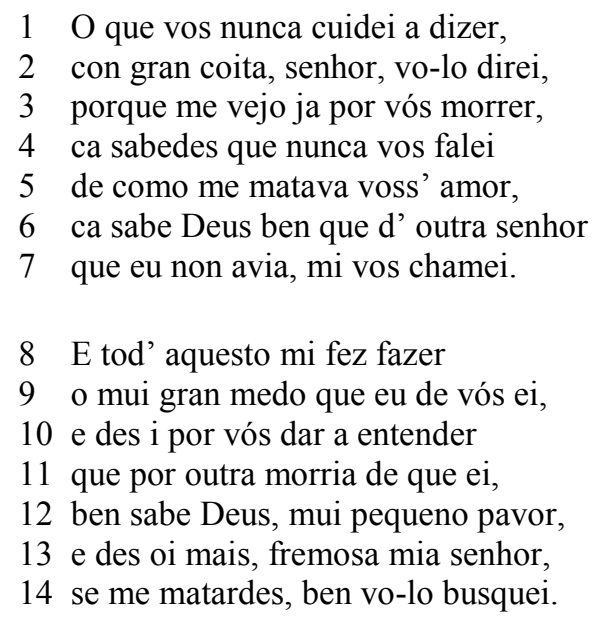

15 E creede que averei prazer

16 de me matardes, pois eu certo sei,

17 que esso pouco que ei de viver

18 que nenhun prazer nunca veerei,

19 e por que soo d' esto sabedor,

20 se mi quiserdes dar morte, senhor,

21 por gran mercee vo-lo terrei ${ }^{10}$.

Nos detendremos en dos problemas de hipometría, casos en los que falta una sílaba en el conteo métrico de la composición ${ }^{11}$, relevados aquí por los dos editores más importantes del CDD, H. Lang (1894) y J. J. Nunes [1932 (1972)]. Estos serán cotejados con ejemplos de otras dos cantigas del rey que presentan problemas métricos similares: Pois que vós, Deus, amigo, quer guisar (T 1; B 524; VK 107), y A tal estado m'adusse, senhor (T 2; B 525; VK 108). Es importante destacar aquí que poseemos la notación musical de forma casi completa de estas dos últimas piezas.

\footnotetext{
${ }^{9}$ Los topoi son "clichês fixos ou esquemas do pensar e da expressão" (Kayser en Spina 1966: 46)

${ }^{10}$ La edición filológica es nuestra y revisa varias lecciones erróneas de Lang: (v. 6) sabedes, (v. 7) que eu nom avia pavor nem ei

${ }^{11}$ En la historia de la edición de la lírica gallego-portuguesa se ha tendido a explicar estas faltas a partir de problemas de copia de los amanuenses. Y, aunque en algunos casos puede ser así, debe también pensarse en las características mismas de esta tradición lírica, como dijimos, ligada a la oralidad y el canto.
} 
Volviendo a la primera, para el verso 8 las lecciones de $\mathrm{B}$ y $\mathrm{V}$ son coincidentes $^{12}$ :

E todaquesto mi fez fazer (B)

E todaquesto mi fez fazer $(\mathrm{V})$

Ante la falta de una sílaba en el verso, Lang propuso la siguiente enmienda: "todo aquesto" (1894: 32-3), y Nunes, siguiendo a Michaëlis de Vasconcelos: "fezo fazer" [1932 (1972: 114-5)], enmiendas legitimadas desde el punto de vista filológico, pero no requeridas por la melodía, en la medida que ésta presenta una asignación irregular de notas por cada silaba En este sentido, es interesante recordar la llamada de atención que realiza Ferreira (2005: 58) sobre los casos de verso hipométrico en contexto silábico del códice E de las CSM. Una mano posterior corrigió diferentes problemas métrico-melódicos, pero dejó intactos los casos en que las melodías son de tipo neumático, es decir, cercanas al ámbito de lo melismático. La solución es simple: al ser la relación entre las silabas del verso y las notas de la melodía de carácter irregular, los casos de hipometría pueden diluirse en la performance de la pieza. De este modo el musicólogo portugués justificó su decisión de dejar intacto este verso 8:

\footnotetext{
A irregularidade inicial e final da articulação silábica torna plausível a hipometria do verso oito, já que a segunda sílaba, "tod", a que teoricamente caberiam apenas duas curtas notas de passagem, tenderia a reclamar, pela sua função semântica, o peso declamatório da terceira posição silábica, a absorção do conteúdo musical desta última pela segunda sílaba é uma operação simples e melodicamente neutra $(2005: 60){ }^{13}$.
}

Independientemente de los presuntos problemas de distribución de texto (alineamientos defectuosos) que apuntan a otorgan una determinada regularidad y sensibilidad declamatoria ${ }^{14}$, nosotros proponemos aproximarnos al verso 8 de forma práctica. A partir de la lectura de la notación musical puede verse el modo en que las nueve o diez sílabas del verso se encuentran articuladas con treinta y cuatro o treinta y seis sonidos que, independientemente de su duración relativa, son distribuidos de manera irregular (siendo difícil la hipótesis de que se cantaran todos los sonidos de

\footnotetext{
${ }^{12}$ En T solo se lee: "E todaquesto mi fez", ya que el folio está roto.

${ }^{13}$ Es interesante destacar que en su versión de esta cantiga la musicóloga e interprete musical Paulina Ceremuźyńska (2006) ha mantenido, en ambos casos, las enmiendas de Lang.

${ }^{14}$ Algunas de estas cuestiones merecerían futuras revisiones ya que en algunos casos proponen una interpretación algo arbitraria.
} 
manera de hacer durar a cada sílaba la misma cantidad de tiempo $)^{15}$. La articulación podría organizarse, entre otras variables, de la siguiente manera: ${ }^{16}$

\begin{tabular}{|l|l|l|l|l|l|l|l|l|l|l|}
\hline v.1 & O & que & vos & nun & ca & cui & dei & a & di & zer \\
\hline v.8 & e & tod & a & ques & to & mi & fe & -----[e/z-- & fa & zer \\
\hline Nota $^{17}$ & la, sol, sol, fa & la, si & do, si, la & $\begin{array}{l}\text { la, sol, fa } \\
\text { (la, sol) }\end{array}$ & $\begin{array}{l}\text { sol, la, } \\
\text { si }\end{array}$ & do, si, la & $\begin{array}{l}\text { la, sol, } \\
\text { la }\end{array}$ & $\begin{array}{l}\text { la, sol, fa, } \\
\text { mi, }\end{array}$ & $\begin{array}{l}\text { la, sol, fa, mi, } \\
\text { re, mi, re, do, }\end{array}$ & do \\
\hline
\end{tabular}

Lo mismo puede decirse para el hipométrico verso 21 , de este modo en $\mathrm{B} \mathrm{yV}^{18}$ :

Por gram mercee uolo teirei (B)

por gran mercee uolo terrey(V)

Aquí nuevamente Lang y Nunes buscaron la isometría del verso, enmendando el primero en "vo-lo eu terrei” (1894: 32-3) y el segundo en "por mui gram mercee" [1932

(1972: 114-5)]. Como bien dice Ferreira (2005: 61), la notación musical es el elemento que nos permite dejar la lección tal como la testimonian $\mathrm{BV}^{19}$ :

No que diz respeito à hipometria do verso final da última estrofe, temos que a música conservada, apesar de incompleta, exibe a mesma irregularidade articulatória da frase inicial pelo que se acomoda bem à ausência de uma sílaba.

Lo que se traduce en el siguiente cuadro ${ }^{20}$ :

\begin{tabular}{|l|l|l|l|l|l|l|l|l|l|l|}
\hline v. 7 & que & eu & non & a & vi & a & mi & vos & cha & mei \\
\hline v. 21 & por & gran & mer & ce & e & vo & ---lo & te & [e] & rrei \\
\hline Nota $^{21}$ & re & re, mi, & re, mi & fa, sol, & fa, mi, & (re, do $)$ & (re) & (mi, re) & mi, re, & do, re \\
\hline
\end{tabular}

${ }^{15}$ Operación llevada a cabo a partir de la transcripción y reconstrucción de Ferreira.

${ }^{16}$ Debe destacarse que esta, y las siguientes, son solo una de las posibilidades de articulación, aunque tal vez una de las más factibles. La extensión de la sílaba en cuestión es marcada en todos los cuadros a través del uso de la unión de corchete, negrita y cursiva. Nos basamos en cuestiones relacionadas con la gramática y fonética históricas, relacionadas mayormente con los verbos ver/veer, ter/teer, y otros términos y su relación con las vocales largas o breves latinas o la caída del archifonema /N/. No obstante, es importante entender que el intérprete posiblemente podría modificar la distribución entre las silabas y las notas, e incluso su duración. De todas formas, cualquiera fuera la distribución utilizada, no alteraría el carácter rítmico irregular planteado por la música.

${ }^{17}$ Las notas se corresponden con la transcripción y reconstrucción de Ferreira.

${ }^{18}$ En T solo se lee "uolo terrey", ya que el folio está roto.

${ }^{19}$ La lección de $\mathrm{T}$ es ilegible.

${ }^{20}$ En una de sus posibilidades de articulación.

${ }^{21}$ Las notas se corresponden con la transcripción y reconstrucción de Ferreira. 


\begin{tabular}{|l|l|l|l|l|l|l|l|l|l|l|}
\hline & & re, do & & la, sol & (mi, re) & & & & do & \\
\hline
\end{tabular}

Un caso similar se da en el hipométrico verso 14 de Pois que vós, Deus... ${ }^{22}$ :

pedide lhi mercee pormj (T)

Pedidelhi mercee por mi (B)

pedi de lhi merçee por mi (V)

Aunque esta es la lección compartida por los tres testimonios, Lang (1894: 31-2) y Nunes [1932 (1972: 111-2)] enmendaron el verso a través de la interpolación del pronombre personal vós, justificado en el texto por el destinatario de la cantiga (la senhor), y cohesionado en el verso por su relación con el pronombre personal en función término $m i$ : «pedide-lhi vós mercee por mi» ${ }^{23}$. Pero nuevamente a partir de la lectura de la notación musical puede verse el modo en que las nueve o diez sílabas del verso en cuestión se encuentran articuladas con diecinueve sonidos que, independientemente de su duración relativa, son asignados de manera irregular (siendo difícil la hipótesis de que se cantaran todos los sonidos de manera de hacer durar a cada sílaba lo misma cantidad de tiempo). La articulación podría organizarse aquí de la siguiente manera ${ }^{24}$ :

\begin{tabular}{|l|l|l|l|l|l|l|l|l|l|l|}
\hline v.3 & vos & ei & lhi & quei & ra & des & tan & to & ro & gar \\
\hline v.14 & pe & di & de & lhi & mer & ce & e & po & [o/r & mi \\
\hline Nota $^{25}$ & la & si & do-re & la & fa-mi-re & fa & la & la-fa-re-do & re-mi-re & $\begin{array}{c}\text { re- } \\
\text { do }\end{array}$ \\
\hline
\end{tabular}

Por el contrario, en la cantiga $A$ tal estado... ${ }^{26}$ los cuartos versos de todas las estrofas son hipermétricos, pero desde nuestro punto de vista se trataría aquí de una 'falsa hipermetría'. Estos son los versos:

\footnotetext{
${ }^{22}$ Pois que vos, Deus, amigo, quer guisar/d' irdes a terra d' u é mia senhor,/rogo-vos ora que por qual amor/vos ei lhi queirades tanto rogar/que se doia ja do meu mal.//E d' irdes i tenh' eu que mi fará/Deus gran ben, pois-la podedes veer,/e, amigo, punhad' én lhi dizer,/pois tanto mal sofro, gran sazon á,/que se doia ja do meu mal.//E pois que vos Deus aguisa d' ir i,/tenh' eu que mi fez el i mui gran ben,/e pois sabede-lo mal que mi vén,/pedide-lhi mercee por mi,/que se doia ja do meu mal.

${ }^{23}$ Así dice Nunes [1932 (1972: 111-2)]en la nota 14 a esta cantiga: «A admitirmos a correção vos proposta por Lang, êste pron. contrapõe-se a por mi, isto é, em meu lugar; de apôsto a mercee serve o refram».

${ }^{24}$ En una de sus posibilidades de articulación.

${ }^{25}$ Las notas se corresponden con la transcripción y reconstrucción de Ferreira.
} 
(4) nen veerei ja en quant' eu vivo for, (estrofa I)

nen veerei ja, esto creede ben, (estrofa II)

prazer, nen veerei ja, per boa fe, (estrofa III)

Lang (1894: 121) y Nunes llamaron la atención sobre ellos en nota al pie: «Notese que veerei (versos 4, 9, 14) conta-se por bissílabo» [1932 (1972: 113)]. Como deja claro R. Lapa (1977: 229): «Os verbos seer e veer, de uso constante, são muitas veces monossilábicos, e a crase métrica afecta sobretudo os grupos protónicos; see-re-des, vee-rei, etc». Pero hemos de subrayar que esto no sucede de forma regular en BV, sino que por el contrario, un verbo con alta frecuencia de aparición como veer suele ser bisilábico, y su forma conjugada veerei varía entre la forma bisílabica y la trisilábica. Esto queda claro en el $C D D$, donde veer es siempre contado métricamente como bisílabo. Su forma conjugada, veerei, funciona como bisílabo en esta cantiga ${ }^{27}$ y en una de amor donde la simplificación de la $e$ deja subrayado este hecho gráficamente:

(5) de que enton verei, prazer (v. 10. Quant' eu, fremosa mia senhor. B 501, V 84)

además de en otra de amigo, en la que tanto el copista de B como el de V vacilan entre una y otra forma:

(6) e verei prazer de mi (v. 5)/ e veerei de min prazer (v. 11) (Amigo, pois vos non vi. B 599, V 202) ${ }^{28}$

Del mismo modo, solo dos casos atestiguan su forma trisilábica:

(7) E non sei quando vos ar veerei (v. 13. Senhor, pois que m'agora Deus guisou. B 507,V 90.)

(8) que nenhun prazer nunca veerei (v. 18. O que vos nunca cuidei a dizer. T 3, B 526, V 109)

\footnotetext{
${ }^{26}$ A tal estado mi adusse, senhor,o vosso ben e vosso parecer,que non vejo de mi nen d' al prazer,/nen veerei ja en quant' eu vivo for,/u non vir-vos que eu por meu mal vi.//E queria mia mort' e non mi vén,/senhor, porque tamanh' é o meu mal/que non vejo prazer de min nen d' al i/nen veerei ja, esto creede ben,/u non vir-vos que eu por meu mal vi.//E pois meu feito, senhor, assi é,/querria ja mia morte, pois que non/vejo de mi nen d' al, nulha sazon,/prazer, nen veerei ja, per boa fe,/u non vir-vos, que eu por meu mal $\mathrm{vi} / /$ pois non avedes mercee de min.

${ }^{27}$ Con relación a esta variación lingüística, es interesante destacar que la cantiga de amor Senhor e lume d' estes olhos meus, de Joan Soarez Coelho (A 172, B 323), cuya fiinda mantiene una estrecha relación intertextual con esta cantiga, cuenta el verbo veerei como trisílabo: Nen veerei, senhor, mentr' eu viver/se non vir-vos -ou mala morte- prazer!.

${ }^{28}$ Lo mismo sucede la cantiga de amor Senhor non vós pés, se me guisar Deus (B 528,, $\mathrm{V} 131$ ) con la forma verán-veerán: nunca verán estes olhos meus (v.4)/ que non veeran prazer d' al nen de min (v. 16), siendo ambos métricamente iguales.
} 
Desde nuestro punto de vista, el manuscrito deja claro que el amanuense que copia la música comprende que se trata allí de un bisílabo y escribe la notación musical teniendo esto en cuenta ${ }^{29}$, hecho que pone de manifiesto Ferreira (2005: 59):

\begin{abstract}
A hipermetria do quarto verso de todas as estrofes aparece diluído, na nossa edição, no terceiro neuma, que é assim distribuído por duas sílabas. A escolha desta ligadura funda-se na observação de que o segundo ponto oblíquo e a plica descendente estão nela sobrepostos, o que sugere um acrescento devido à presença de uma sílaba adicional.
\end{abstract}

Por eso no comprendemos por qué en su transcripción paleográfica y edición crítica de la misma lee veerei como un trisílabo (Ferreira 2005: 131):

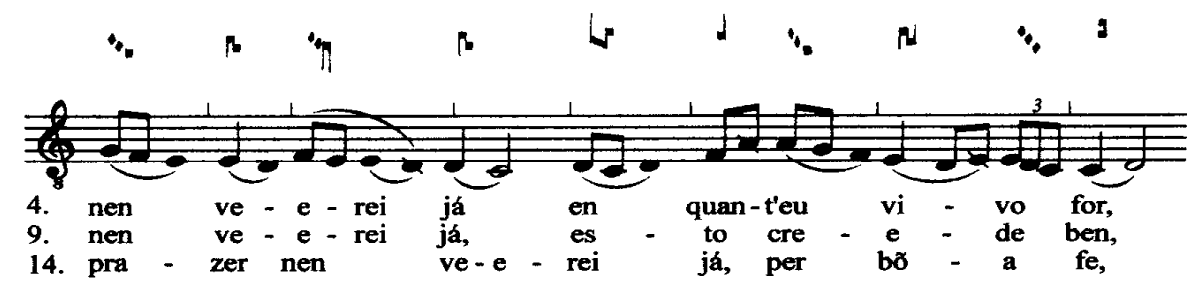

Nos encontramos en esta pieza con diez sílabas y veintisiete notas articuladas de manera irregular que, desde nuestro punto de vista, podrían ordenarse del siguiente modo, tomando este verbo como un bisílabo: Esta es nuestra propuesta.

(9)

\begin{tabular}{|c|c|c|c|c|c|c|c|c|c|c|}
\hline & $8 x^{2}$ & 75 & 53 & 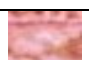 & $\sin$ & 1050904 & 108 & 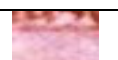 & rot & PIIII \\
\hline & Alich & uet & $20 \%$ & $\ln 1$ & gase & gerentin & reas & myi & 130. & 1 \\
\hline Sílaba & nen & vee & rei & ja & en & quan't & $\mathrm{eu}$ & vi & vo & for \\
\hline Nota & sol-fa-mi & mi-re & fa-mi-(mi)-re & re-do & re-do-re & fa-la & la-sol-fa & mi-re-mi & mi-re-do & do-re \\
\hline
\end{tabular}

Así, en una instancia performativa, tanto únicamente vocal como con acompañamiento instrumental, la organización de la versificación se presentaría con una estética sonora totalmente diferente a lo registrado en los textos, ordenándose a partir de

\footnotetext{
${ }^{29}$ Nuevamente nos sorprende que en su versión de esta cantiga la musicóloga y música Paulina Ceremuźyńska (2006) haya mantenido la enminenda de Lang y Nunes.
} 
los parámetros de la melodía: cantidad de sonidos por sílaba y duración y altura de los mismos.

\section{Conclusión}

De lo dicho hasta aquí se desprende que es necesario aproximarnos a la edición de la lírica profana gallego-portuguesa desde un trabajo interdisciplinario filológicomusicológico que conciba la composición poética como un texto cantado, desenvolviéndose en un tiempo mucho más extenso que el de la lectura regular oral que hoy utilizamos para la poesía moderna. La melodía es aquí el elemento principal, ya que nos permite extender las sílabas en el tiempo o, por el contrario, quebrarlas. Esta aproximación trae aparejada la elaboración de una pragmática que, a partir del cotejo y estudio de los casos de hipo e hipermetría, el análisis de casos de hiatos, dialefas y sinalefas $^{30}$, la relación de la duración de las notas musicales con las sílabas largas y breves del latín, latentes en la lengua medieval, y en algún punto, la confrontación de todos estos puntos con las tardías Poéticas gallego-portuguesas y provenzales ${ }^{31}$, siente las bases para un punto medio entre ese recurso a la enmienda y la conservación íntegra del texto.

\section{Bibliografía}

Arias Freixedo, Xosé Bieito

2004, "Diverxencias textuais entre o Cancioneiro da Ajuda e os apógrafos italianos da Biblioteca Nacional de Lisboa e da Vaticana", en: A lingua galega, historia e actualidade Actas do I Congreso Internacional, 16-20 de setembro de 1996, Álvarez Blanco, María Rosario Editor: Fernández Rei, Francisco, Santamarina (eds.), Consello da Cultura Galega / Instituto da Lingua Galega: Santiago de Compostela, vol. III, pp. 717729.

Asensio, Eugenio

${ }^{30}$ Sin olvidar las intervenciones de los copistas a la hora de transcribir, tendientes a hacer versos isométricos, como señaló Arias Freixedo (2004: 717-29) en el cotejo de ciertas divergencias entre A y $\mathrm{B} / \mathrm{V}$.

${ }^{31} \mathrm{El}$ Arte de Trovar contenido en B, y las Leys d'amors. 
1970, Poética y realidad en el Cancionero Peninsular de la Edad Media, Madrid: Gredos.

Ceremuźyńska, Paulina

2006, Cantigas de amor e de amigo. Cantigas profanas galego-portuguesas dos séculos XIII e XIV. Santiago de Compostela: Xunta de Galicia [CD].

Ferreira, M.P.

2005, Cantus coronatus: 7 cantigas d'el Rei Dom Dinis, Kassel: Reichenberg.

Gonçalves, Elsa

1991, Poesia de Rei: três notas dionisinas, Lisboa: Cosmos.

Gröber, Gustav

1877, "Die Liedersammlungen der Troubadours", Romanische Studien, II, pp. 337-670.

Lang, Henry R.

1894, Das Liederbuch des Königs Denis von Portugal, Halle: Max Niemeyer.

Nunes, José Joaquim

1932 (1972), Cantigas d'amor dos trovadores galego-portugueses, Edição crítica, acompanhada de introdução, comentário e glossário, Coimbra: Imprensa da Universidade.

Rio Riande, Ma. Gimena del y Germán Pablo Rossi

2008a, "Circulación de textos por el Camino de Santiago. El caso de la lírica dionisina en su dimensión poética y musical", en Actas del Congreso In Marsupiis Peregrinorum. Circulación de textos e imaxes arredor do Camiño de Santiago na Idade Media, Santiago de Compostela (en prensa).

2008b, "Sobre musicología y crítica textual: la edición del Cancionero del rey Don Denis", en Actas del VIII Congreso Nacional de AJIHLE, Barcelona (en prensa).

Sharrer, Harvey L. 
1992, "Fragmentos de sete cantigas d'amor de D. Dinis, musicadas-uma descoberta"; en: Actas do IV Congresso da Asociação Hispânica de Literatura Medieval, Lisboa: Cosmos, pp. 13-29.

Spina, Segismundo

1966, Do formalismo estético trovadoresco. Boletim núm. 300, Cadeira de Lit. Portuguesa, núm. 16, São Paulo. 